Psychology of Language and Communication 2012, Vol. 16, No. 2

VERSITAOPEN

DOI: $10.2478 / \mathrm{v} 10057-012-0007-7$

\author{
JOANNA RĄCZASZEK-LEONARDI \\ University of Warsaw
}

\title{
TYPES OF INTEGRATION IN A THEORY OF LANGUAGE
}

\begin{abstract}
In the face of the complexity of language as an object of study, it becomes crucial for researchers who investigate its various facets to communicate and to understand each-others' terminology, methods and results. The feasibility and utility of striving for the elegance of formal models of isolated aspects of the linguistic system (for example, set of generative rules in an individual's head) are called into question: a theory of language needs to account for how it functions in multiple systems and on multiple time-scales. This short introduction to the special issue on Language as Social Coordination situates works in this issue on the map of collective effort to formulate such a theory. It is also a reflection on the form of a theory of language that could integrate this variety of data and results.
\end{abstract}

Key words: theory of language, computer simulation, language as coordination

\section{Language is a tool for functional organization}

One thing seems to be certain when it comes to a theory of language: it cannot be simple. It seems that for many years, this simplicity was strived for: a theory of language in the form of a set of grammatical rules represented in an individual head which would generate any possible utterance. Yet (1) finding such a set of rules, either for a particular language or for languages in general, has proven difficult and (2) such a view of language leaves out the aspects of language that define its very nature in its "natural habitat" (Schegloff, 1996): namely what it does in and for interactions among people.

Humans are a social species, which means that the criteria for selection of behaviors of the individuals are also dictated by functioning at a social [or interpersonal] level. On the one hand, humans are a species that is particularly capable

Address for correspondence: Joanna Rączaszek-Leonardi, University of Warsaw, Faculty of Psychology, Stawki 5/7, 00-183 Warsaw, Poland. E-mail: raczasze@psych.uw.edu.pl 
of rapidly forming and dissolving functional organizations between and among its members, in order to deal with sudden events or tasks at hand. On the other hand, certain ways of organization stabilize in social structures and institutions, which can be more or less explicit and more or less codified. Failing to see language as one of the indispensable tools for this rapid functional organization and a means to stabilize ways of acting socially, seems to be a rather strange omission, a simplification endorsed by a decreasing number of scientists, mainly those who devoted their work exclusively to the internal cognitive functions of language (Chomsky, 2011). For the rest of us, how language functions in dyads, groups, societies and populations is crucial in order to explain the emergence of its structures, to account for its internal workings in individual brains, and to determine its role in shaping interactive events.

\section{Language works on multiple time-scales}

Assuming that the coordinative role is important, however, leads to a very complex picture of language functioning. Not only humans coordinate linguistically both on-line and off-line, their ontogeny is also preparing for such coordination, and selection of "well-coordinating" structures happens over the time-scale of cultural evolution. Additionally, coordination, concept formation and language diachrony are processes, thus phenomena for which time dimension is crucial. It is not obvious how to link the symbolic nature of linguistic expressions, apparently constituted by discrete, timeless structures, with these dynamic, multi-time-scale processes.

One way of dealing with this complexity and "dual nature" of linguistic phenomena is not to assume that the complexity is due exclusively to (and thus explainable at) the layer of symbolic entities but to see language as a special kind of activity, immersed in a variety of internal and interactive dynamical events. In this way, one may say that linguistic behaviors "only" add to (or subtract possibilities from) the natural dynamics of events, supplying what is necessary for a given dynamics to become functional. Following the theorists of information in living systems (Pattee, 1969, 1982; Polanyi, 1968), we may look at language as a system of constraints that - through the processes of use, learning and evolution by cultural selection - were enabled to act as reliable constraints on dynamical events. By binding relevant degrees of freedom of a system, these constraints make the system functional (Tylén, Fusaroli, \& Rączaszek-Leonardi, in press). To use a more biologically motivated image: by limiting potentially available states of the system, constraints make the system more probable to find itself in those that are beneficial from the point of view of the adaptation to the environment.

This view of language as a system of replicable constraints (for details cf. Rączaszek-Leonardi \& Kelso, 2008; Rączaszek-Leonardi, in press) suggests that the mind-boggling system of levels and time-scales on which relevant processes unfold may hopefully gain some coherence and clarity if linguistic symbols are 
seen as constraints on dynamics. The complexity, obviously, does not go away, but it may perhaps become more manageable. This organizational scheme provides theoretical benefit, facilitating identification of the relevant kinds of systems, dynamics and time-scales and establishing the relations of co-dependency among them. The complexity does not go away precisely because of the relevance of this interdependent multiplicity and the difficulty of "framing" and isolating parts of the linguistic system for studying.

In other words, once we accept the important message from the theory of information in biological systems, that "there is virtually no meaning to symbols outside the context of a complex dynamical organization around which the symbolic constraints have evolved" and that "it is useless to search for meaning in symbols without complementary knowledge of the dynamics being constrained by the symbols" (Pattee, 1987, p. 337), we necessarily admit the following consequence. In the case of language, the meaning of an utterance is not only what it does to the dynamics of an individual on-line (e.g., evoking a certain brain state) but also what it has done to an individual in ontogeny (in repetitive instances of the utterance use), what it does to the dynamics of interaction on-line, and to the dynamics of our earlier social commitments (see e.g., Mac Whinney, 2005; Rączaszek-Leonardi, $2009,2010)$. None of the systems and none of its dynamics stand alone: they are interdependent and intertwined, mutually shaping each other.

\section{Back to the analysis?}

What to do, then, in the face of this complexity? Why not stick to the analytical methods of separating the systems and analyzing them as modular entities: choose a level (motivated by questions we want to ask) and try to create a formalizable model of what is going on within the system? With a bit of collective effort and good will in understanding each other's terminology, perhaps, the modular puzzles of levels and subsystems would fall into place, forming a coherent theory? At least two things make such scenario of the theory construction difficult to realize. One has to do with the possibility to isolate the subsystems and the other with the possibility to formalize their workings.

The first challenge consists in the fact that the mechanisms responsible for the behavior of components may lay at the level of a system including (and consisting of) these components. In other words, just like in the oft-cited example of convection rolls in a liquid (see, e.g. Kelso, 1995) - where a particle goes as dictated by the global pattern formed (by those same particles) in a liquid - the emergent pattern, composed of elements, gains a causal power with respect to those elements. Much as it might sound strange to use such a physical metaphor for the behavior of conscious beings, the gap narrows if one thinks about the behavior of swarms of animals (flocks of birds or schools of fish) in which local interactive mechanisms cause global patterns that, in turn,"enslave" the elements. That such principles may 
be used in explanations of the behavior of people in a situation of collaboration has been shown in experiments on perceptual crossing by Auvray et al. (2009), and modeled in an artificial system by Di Paolo et al. (2008). The property of being in a stable interaction was used as an explanatory concept for the behavior of individual agents. In the case of language, ordering forces and mechanisms from different levels and time-scales have been shown to be present in a single experimental task and to be reflected in reaction times of participants (Rączaszek-Leonardi, 2010). The feature of grammatical gender was shown to influence the on-line objects description proportionally to the congruence of grammatical genders among languages. This indicated that semantic forces acting on the time scale of cultural evolution are present in the laboratory situation. Isolating a system, or a time-scale might thus be excessively difficult and result in oversimplifications.

The second difficulty is linked to the formalizability of the models. Once we admit that dynamics is an inseparable part of the meaning of an expression, constructed here and now, it is increasingly difficult to describe a system only in terms of a formal model. The dynamic side of a system is a substrate comprised of multiple non-linearly interacting elements, whose behavior relies on repetitive, error-prone, stochastic processes and mechanisms of natural selection. Obviously, simplifying descriptions may be designed to predict the outcomes of such processes, but due to the sensitivity to initial conditions and to particular values of many parameters, our descriptions will remain just this, simplifications, and their predictions limited.

\section{Integration through simulation}

Is there any way out of these two crucial difficulties? As is usually the case, such troubles do not prevent scientists from doing research on chosen aspect of language, nor prevent theorists from constructing their - more or less general theories. One of the most promising and encompassing approaches is to explain how language functions by using multi-agent and multi-level computer simulations. In such models it is possible to link the levels of the on-line language functioning (where agents communicate) with the levels and time-scales of language learning (where agents' cognitive systems are shaped for coordination through interaction with 'older agents') and with the levels and time-scales of cultural language evolution (in which the functioning of generations of agents in populations in a given environment set the selection criteria for linguistic structures). There are already many excellent examples of models that focus on various aspects of these complex phenomena. Among them is Smith, Brighton and Kirby's (2002, 2003) work within the iterative learning paradigm, in which they have shown that the compositionality of language is a trait that makes a language system stable in the face of the bottleneck of cultural transmission. In their work on communication in artificial agents Cangelosi and colleagues show the necessity of grounding symbols in perceptual categories on the developmental and evolutionary time- 
scale (see e.g., Cangelosi, 2010). Perhaps the most comprehensive work of Luc Steels and colleagues, encompasses the multiple levels mentioned in multi-agent architectures to ask specific questions about the link between cognition (conceptual categories) and language (e.g. in color categorization - Steels and Belpaeme, 2005) and to construct artificial systems functioning according to the discovered principles in real environments (Loreto \& Steels, 2007; Steels, 2011). Such an approach not only allows formulating an encompassing and coherent theory, but also, if needed, zooming in at the particular aspect, or time-scale, always bearing in mind its inseparability from the rest.

Obviously, computer simulations cannot stand alone. In weaving the fabric of explanation, theoretical work is needed, which links the reflection on the evolution and information in living systems with the theory of language, and, obviously, empirical research on language, which supports predictions of particular mechanisms and allows for the refinement of the models. Through the notion of multiple embedded time-scales and systems, various methodologies and various types of data can be integrated, with researchers collaborating to fill in information about the particular aspects of the models. The data come from:

- corpus studies that show processes on the cultural-evolution timescale, such as diachronic changes (e.g., Tabor, 1994, 1995; Bybee, 2002) but also, on a faster time-scale, such as processes of diffusion of innovations (Altmann et al., 2011) and more rapid social changes in frequency of uses (Cohn et al., 2004).

- studies on language acquisition, from day one (or even earlier) onward, where language is seen as establishing the rhythm of social interaction (Trevarthen \& Daniel, 2005), educating attention (Nomikou et al., submitted) and instilling values (Cowley, 2004). These serve as a basis, for the study how specific utterances link with social experience to socialize cognition (Wygotski (1930/2006); Zinken and Ogiermann, 2011).

- studies of on-line processes, both on the individual level and the level of interaction. Both are approached through the parallel studies of behaviors and patterns of brain activation. Traditional psycholinguistics has provided a substantial body of data on reaction times, errors, grammaticality judgments of individuals (e.g., Gleason \& Ratner, 1997), with some of the findings supported by the brain imaging studies (see e.g., Kutas \& Federmeier, 2011; van Berkum, 2008). More recently the level of interaction came under experimental scrutiny, showing how language coordinates individuals on a physical (McFarland, 2001; Shockley et al., 2003) as well as conceptual level (Pickering \& Garrod, 2004, 2010; Fusaroli \& Tylén, 2012;), in a culturally specific (Sinha, 2009; Zinken, 2008) and value-laden way (Trevarthen \& Aitken, 2001; Hodges, 2007). Also data on this, interactive, level is beginning to be supported by the studies of simultaneous brain activity (Tognoli et al., 2007; Dumas, et al., 2010). 
One particularly interesting approach stands out as able to link several levels and time-scales in experimental studies, namely experimental semiotics. It is a sort of "simulation" of language emergence and evolution in the laboratory, with real participants, in which task design allows for artificial shortening of time scales and observing on-line, learning and "cultural evolution" processes (Galantucci, 2005; Fay, et al., 2010, for a review see Galantucci \& Garrod, 2011). Computer simulations and experimental semiotics coexist in some labs, which fruitfully use both of them, to mutually inspire each other (Kirby et al., 2008; Kirby et al., 2009).

The present volume exemplifies many of the approaches that need to be integrated in language study: from philosophical and evolutionary reflection (Wacewicz \& Żywiczyński, 2012) to experiments on how the language biblinguals actually use changes the value system applied to social situations (Boski \& Iben Youssef, 2012) to corpus-based research on the emergence and spread of linguistic innovation (Paradowski \& Jonak, 2012). A necessity of the integration of methodologies, and finding the place for a new nomothetic approach is stressed in Roberts \& Winters' contribution (Roberts and Winters, 2012). Methodology is also the topic of the last paper (Leonardi, 2012), which summarizes applications of Recurrency Quantification Analysis, a novel way to deal with dynamic processes in complex systems, especially those that comprise local and global levels (like the individual and interactive ones in language). I hope that the relevance of each of these works to the theory of language is clearly visible. Reflection on the overall form of the theory follows.

\section{The form of the theory}

Two kinds of integration seem to be facilitated by employing simulations of the processes of language emergence and use in artificial (or natural) agent-based systems. The first one is the integration of time-scales and levels, which allows observations how parameters and dynamics on one time-scale depend and determine parameters and dynamics on the others. The second kind of integration is due to the computational power of modern machines: they may help account for dynamic processes involved in language functioning which are based on iterative interactions of multiple agents, involving non-linear dependencies, noise and natural selection, and integrate them with symbolic ones. In the second sense the term "integration" has actually a deeper meaning than just "linking" the symbolic and the dynamic level: it means accounting for how a symbolic form accrues meaning by iterative acting (as a constraint) on several time-scales. In this sense "integration" draws on the mathematical concept of cumulating small changes over time.

Simulations may thus show, how, in multiple communicative episodes and multiple learning episodes, over time, constraints accrue controlling power over dynamics. This controlling becomes functional, or adaptive, in the process of natural selection, which acts on constraints, gradually shifting the probability distribution of adaptive and non-adaptive behaviors. 
However such a form of a linguistic theory is very different from what the formal and/or generative models got us used to. It may well be that when building a veridical model of almost any interesting aspect of language one has to give up the hope for elegant formal models and algorithm-like explanations in the spirit of early cognitive science (Good Old-Fashioned Cognitive Science). With the computational simulations of dynamics involved - because of the sensitivity to initial conditions, non-linear responses of the systems to parameter changes and processes of natural selection - we are doomed to the study of "particular cases" (Turing, 1952, p.72). Simulations of non-linear, repetitive, error-prone, stochastically driven processes, as in any physical complex system, will not result in the predictability similar to an algorithmic procedure. This is not due to error (in measurement or performance) but to the very nature of the processes under study. A particular process always remains idiosyncratic, unique, both in individuals under study and in simulations.

It is very important to see the difference between a theory in the form of a generalized, lawfully described, algorithmic model, and a theory based on grasping regularities form the observation and simulation of "particular cases", where time-dependent dynamics and irreversible selection processes interact with symbolically described constraints. Perhaps, since the idiosyncrasy of a particular history of a system and its elements is such an important feature of meaning construction, this difference is one of these things that make us feel the authenticity of the eternal divide between the humanistic accounts of human behavior and the lawful explanations of exact sciences.

\section{Acknowledgements}

The Author is grateful to Elena Cuffari and Riccardo Fusaroli for their helpful comments. The preparation of the Special Issue and this text was supported by Marie Curie Reintegration Grant PERG06-GA-2009-256587 from European Commission, Framework Programme 7.

\section{References}

Altmann, E.G., Pierrehumbert, J.B., Motter, A.E. (2011). Niche as a determinant of word fate in online groups. PLoS ONE, 6 (5), e19009.

Auvray, M., Lenay, C., \& Stewart, J. (2009). Perceptual interactions in a minimalist environment. New Ideas in Psychology, 27, 79-97.

Berkum, J.J.A. van (2008). Understanding sentences in context: What brain waves can tell us. Current directions in psychological science, 17 (6), 376-380.

Boski, P. \& Iben Youssef, K. (2012). Consequences of linguistic frame switching: Cognitive and motivational shifts in bilingual Tunisians. Psychology of Language and Communication, 16 (2), 65-85.

Bybee, J. (2002). Word frequency and context of use in the lexical diffusion of phonetically conditioned sound change. Language Variation and Change, 14, 261-290. 
Cangelosi, A. (2010). Grounding language in action and perception: From cognitive agents to humanoid robots. Physics of Life Reviews, 7 (2), 139-151.

Chomsky, N. (2011). Language and other cognitive systems. What is special about language? Language Learning and Development, 7, 263-278.

Cohn, M.A., Mehl, M.R., \& Pennebaker, J.W. (2004). Linguistic markers of psychological change surrounding September 11, 2001. Psychological Science, 15, 687-693.

Cowley, S.J. (2004). Contextualizing bodies: How human responsiveness constrains distributed cognition. Language Sciences, 26, 565-591.

Di Paolo, E.A., Rohde, M., \& Iizuka, H. (2008). Sensitivity to social contingency or stability of interaction? Modelling the dynamics of perceptual crossing. New Ideas in Psychology, 26, 278-294.

Dumas, G., Nadel, J., Soussignan, R., Martinerie, J., \& Garnero, L. (2010). Inter-Brain Synchronization during Social Interaction. PLoS ONE, 5 (8), e12166.

Fay, N., Garrod, S., Roberts, L.L., \& Swoboda, N. (2010). The interactive evolution of human communication systems. Cognitive Science, 34, 351-386.

Fusaroli, R. \& Tylén, K. (2012). Carving Language for Social Interaction: a dynamic approach. Interaction studies, 13 (1), 103-123.

Galantucci, B. (2005). An experimental study of the emergence of human communication systems. Cognitive Science, 29 (5), 737-767.

Galantucci, B. \& Garrod, S. (2011). Experimental semiotics: A review. Frontiers in Human Neuroscience, 5:11. doi:10.3389/fnhum.2011.00011

Gleason, J.B. \& Ratner, N.B. (1997). Psycholinguistics, 2nd edition. New York: Harcourt Brace.

Hodges, B.H. (2007). Values define fields: The intentional dynamics of driving, carrying, leading, negotiating, and conversing. Ecological Psychology, 19, 153-178.

Kelso, J.A.S. (1995). Dynamic patterns: The self-organization of brain and behavior. Cambridge, MA: The MIT Press.

Kirby, S., Cornish, H., \& Smith, K. (2008). Cumulative cultural evolution in the laboratory: An experimental approach to the origins of structure in human language. Proceedings of the National Academy of Sciences, 105 (31), 10681-10686.

Kirby, S., Christiansen, M., \& Chater, N. (2009). Syntax as an adaptation to the learner. In D. Bickerton \& E. Szathmáry (Eds.), Biological foundations and origin of syntax (pp. 325-343). Cambridge, MA: MIT Press.

Kutas, M. \& Federmeier, K.D. (2011). Thirty years and counting: Finding meaning in the N400 component of the event related brain potential (ERP). Annual Review of Psychology, 62, 621-647.

Leonardi, G. (2012). The study of language and conversation with recurrence analysis methods. Psychology of Language and Communication, 16 (2), 87-105.

Loreto, V. \& Steels, L. (2007). Social dynamics: Emergence of language. Nature Physics, 3, 758-760.

MacWhinney, B. (2005). The emergence of linguistic form in time. Connection Science, 17 (3-4), 191-211. 
McFarland, D.H. (2001). Respiratory markers of conversational interaction. fournal of Speech, Language, and Hearing Research, 44, 128-143.

Nomikou, I., Szufnarowska, J., \& Rohlfing, K. J. (submitted). Educating attention: Recruiting, maintaining and framing eye-contact in early natural mother-infant interactions.

Paradowski, M. \& Jonak, Ł. (2012). Diffusion of linguistic innovation as social coordination. Psychology of Language and Communication, 16 (2), 53-64.

Pattee, H.H. (1969). How does a molecule become a message? Developmental Biology Supplement, 3, 1-16.

Pattee, H.H. (1982). Cell psychology: An evolutionary approach to the symbol-matter problem. Cognition and Brain Theory, 5 (4), 325-341.

Pattee, H.H. (1987) Instabilities and information in biological self-organization. In F.E. Yates (Ed.), Self-organizing systems. The emergence of order (pp. 325-338). New York: Plenum.

Pickering, M.J. \& Garrod, S. (2004). Toward a mechanistic psychology of dialogue. Behavioral and Brain Sciences, 27, 169-225.

Pickering, M.J. \& Garrod, S. (in press). An integrated theory of language production and comprehension. Behavioral and Brain Sciences.

Polanyi, M. (1968). Life's irreducible structure. Science, 160, 1308-1312.

Rączaszek-Leonardi, J. (2009). Symbols as constraints: the structuring role of dynamics and self-organization in natural language. Pragmatics and Cognition, 17 (3), 653-676.

Rączaszek-Leonardi, J. (2010). Multiple time-scales of language dynamics: An example from psycholinguistics. Ecological Psychology, 22, 4, 269-285.

Rączaszek-Leonardi, J. (in press). Language as a system of replicable constraints. In H.H. Pattee, J. Rączaszek-Leonardi (Eds.), Laws, language and life: Howard Pattee's classic papers on the physics of symbols. Springer.

Rączaszek-Leonardi, J. \& Cowley, S.J. (2012). The evolution of language as controlled collectivity. Interaction Studies, 13 (1), 1-16.

Rączaszek-Leonardi, J. \& Kelso, J.A.S. (2008) Reconciling symbolic and dynamic aspects of language: Toward a dynamic psycholinguistics. New Ideas in Psychology, 26, 193-207.

Roberts, S., \& Winters, J. (2012). Social structure and language structure: The new nomothetic approach. Psychology of Language and Communication, 16 (2), 11-34.

Schegloff, E.A. (1996). Turn organization: One intersection of grammar and interaction. In E. Ochs, E.A. Schegloff, \& S. Thompson (Eds.), Interaction and grammar (pp. 52-133). Cambridge, UK: Cambridge University Press.

Shockley, K., Santana, M.-V., \& Fowler, C.A. (2003). Mutual interpersonal postural constraints are involved in cooperative conversation. Fournal of Experimental Psychology. Human Perception and Performance, 29 (2), 326-332.

Sinha, C. (2009). Language as biocultural niche and social institution. In V. Evans \& S. Pourcel (Eds.), New directions in cognitive linguistics (pp. 289-310). Amsterdam: John Benjamins. 
Smith, K., Brighton, H., \& Kirby, S. (2002). Language evolution in a multi-agent model: The cultural emergence of compositional structure. Retrieved from: http://www3. isrl.illinois.edu/ junwang4/langev/localcopy/pdf/smith02languageEvolution.pdf Smith, K., Brighton, H., \& Kirby, S. (2003). Complex systems in language evolution: The cultural emergence of compositional structure. Advances in Complex Systems, 6, 537-558.

Steels, L. (2006). Experiments on the emergence of human communication. Trends in Cognitive Sciences, 10, 347-349.

Steels, L. (2011). Modeling the cultural evolution of language. Physics of Life Reviews, 8, 339-356.

Steels, L. \& Belpaeme, T. (2005). Coordinating perceptually grounded categories through language: A case study for colour. Behavioral and Brain Sciences, 28, 469-489.

Tabor, W. (1994). Syntactic innovation: A connectionist model. Ph.D. dissertation, Stanford University.

Tabor, W. (1995). Lexical change as nonlinear interpolation. In J.D. Moore \& J.F. Lehman (Eds.), Proceedings of the 17th Annual Cognitive Science Conference (pp. 242-247). Hillsdale, NJ: Lawrence Erlbaum Associates.

Tognoli, E., Lagarde, J., DeGuzman, G.C., \& Kelso, J.A.S. (2007). The phi complex as a neuromarker of human social coordination. Proceedings of the National Academy of Science, 104, 8190-8195.

Trevarthen, C. \& Aitken, K.J. (2001). Infant intersubjectivity: Research, theory and clinical application. Fournal of Child Psychology and Psychiatry, 42 (1), 3-48.

Trevarthen, C. \& Daniel, S. (2005). Disorganized rhythm and synchrony: Early signs of autism and Rett syndrome. Brain \& Development, 27, 25-34.

Turing, A.M. (1952). The chemical basis of morphogenesis. Philosophical Transactions Royal Society of London B, 237, 37-72.

Tylén, K., Fusaroli, R. \& Raczaszek-Leonardi, J. (in press). Dialogue as interpersonal synergy. New Ideas in Psychology.

Wacewicz, S. \& Żywiczyński, P. (2012). Human Honest Signalling and Nonverbal Communication. Psychology of Language and Communication, 16 (2), 32-52.

Wygotski, L.S. (1930/2006). Narzędzie i znak w rozwoju dziecka. Warsaw: Wydawnictwo Naukowe PWN. English translation: Tool and symbol in child development. In R. van der Veer \& J. Valsiner (Eds.), The Vygotsky reader. Cambridge, MA: Blackwell, 1994. Available at: http://www.marxists.org/archive/ vygotsky/works/1934/tool-symbol.htm

Zinken, J. (2008). The metaphor of 'linguistic relativity'. History and Philosophy of Psychology, 10 (2), 1-10.

Zinken, J., Ogiermann, E. (2011). How to propose an action as objectively necessary: The case of Polish trzeba $x$ ('one has to $\mathrm{x}$ '). Research on Language and Social Interaction, 44 (3), 263-287. 